\title{
シミュレーションによる魚群行動の成群機構に関する考察*
}

$$
\text { モハメッドアリドウスタリ }{ }^{* *} \text { 三 宮 信 夫 }{ }^{* * *}
$$

\section{A Simulation Study on Schooling Mechanism in Fish Behavior*}

\author{
Mohammad Ali Doustari ${ }^{* *}$ and Nobuo SANNOMIYA***
}

\section{Introduction}

In our earlier papers ${ }^{1)}$, a mathematical model has been proposed for schooling behavior of fish using observation data from a water tank experiment. Each fish in a school regulates his movement based on the information which he receives from the members in school. However, the mechanism of school behavior and information exchange has not been clear yet.

It is well known that there exists no leader in a fish school $^{3), 4)}$. In this paper, we consider school behavior of fish as an example of autonomous decentralized systems. The autonomous decentralized mechanism is considered to be constructed not by command of the supervisor, but by information exchange among fish. The mechanism is investigated by carrying out computer simulation.

\section{Mathematical model}

Let the position and the velocity of individual fish $i$ be $x_{i}$ and $v_{i}$, respectively, where $x_{i}, v_{i} \in R^{2}$. Then the motion of fish in a school can be described by

$$
\begin{aligned}
& \dot{x}_{i}=v_{i} \\
& m \dot{v}_{i}=F_{i}\left(t, x_{1}, v_{1}, x_{2}, v_{2}, \cdots, x_{N_{f}}, v_{N_{f}}\right) \\
& \quad i=1,2, \cdots, N_{f}
\end{aligned}
$$

where $N_{f}$ is the number of individuals in school and $m$ is the mean mass of the individuals. $F_{i}$ is the resultant of all forces which cause the motion of individual $i$. In our model, attention

* 原稿受付 1992. $\dot{6} .10$

** 京都工芸緎維大学 大学院 Graduate School, Kyoto Institute of Technology, Faculty of Engineering and Design ; Matsugasaki, Sakyo-ku, Kyoto 606, JAPAN

*** 京都工芸繊維大学 工芸学部 Kyoto Institute of Technology, Faculty of Engineering and Design; ditto.

Key Words : modeling, autonomous decentralized system, simulation, fish behavior, ecological system. is paid to the mechanism of schooling behavior. Then $F_{i}$ consists of two components, i.e. $F_{i}=$ $F_{i 1}+F_{i 2}$, which are given as follows.

\subsection{Force due to his own swimming ability}

An individual fish has a character of swimming forward with a constant speed (called the characteristic velocity) when any other causes do not exist for the motion of fish. The character is expressed by ${ }^{2)}$

$$
F_{i 1}=-a_{i}^{1}\left(\left\|v_{i}\right\|-a_{i}^{2}\right)\left(\left\|v_{i}\right\|-a_{i}^{3}\right) v_{i}
$$

where $0<a_{i}^{2}<a_{i}^{3}$. As a result of phase plane analysis, in the case of $a_{i}^{1}>0$, the characteristic velocity of individual $i$ is given by $a_{i}^{3}$, and in the case of $a_{i}^{1}<0$, the characteristic velocity is $a_{i}^{2}$.

\subsection{Interaction among other individuals in school}

An individual fish regulates his movement, i.e. speed and direction, with the positions and the velocities of other individuals in school. The character is given $\mathrm{by}^{2}$

$$
\begin{gathered}
F_{i 2}=\sum_{j \in N_{b}(i)} b_{i}\left(r_{i j}\right) \frac{x_{j}-x_{i}}{r_{i j}}+\sum_{j \in N_{c}(i)} c_{i}\left(r_{i j}\right) \frac{v_{j}-v_{i}}{M_{c}} \\
b_{i}\left(r_{i j}\right)=\left\{\begin{array}{lr}
\frac{\left(k_{b i}^{2}-k_{b i}^{1}\right) r_{i j}}{\alpha_{i 1}+k_{b i}^{1}}, & \text { for } 0<r_{i j} \leq \alpha_{i 1} \\
k_{b i}^{2}, & \text { for } \alpha_{i 1}<r_{i j} \leq \alpha_{2} \\
0, & \text { for } r_{i j}>\alpha_{2}
\end{array}\right. \\
c_{i}\left(r_{i j}\right)= \begin{cases}k_{c i}, & \text { for } 0<r_{i j} \leq \delta \\
0, & \text { for } r_{i j}>\delta\end{cases}
\end{gathered}
$$

where $r_{i j}=\left\|x_{j}-x_{i}\right\|$. The first term of (3) is an interactive force to keep a proper distance between neighboring individuals. The second term is a schooling force to make the velocity of each fish uniform. In (3), $N_{b}(i)$ and $N_{c}(i)$ are the subsets of $\left\{1,2, \cdots, N_{f}\right\}$ whose element consists of 
Table 1 Parameter estimates $\left(N_{f}=5\right)$

\begin{tabular}{c|ccccccc}
\hline$i$ & $a_{i}^{1}$ & $a_{i}^{2}$ & $a_{i}^{3}$ & $k_{b i}^{1}$ & $k_{b i}^{2}$ & $k_{c i}$ & $\alpha_{i 1}$ \\
\hline 1 & -0.00366 & 11.9 & 35.0 & -6.20 & 4.20 & 1.570 & 8.47 \\
2 & -0.00275 & 11.0 & 38.4 & -6.40 & 4.38 & 1.310 & 8.44 \\
3 & -0.00330 & 10.9 & 37.9 & -4.40 & 3.11 & 1.490 & 8.35 \\
4 & -0.00180 & 10.6 & 46.4 & -5.60 & 2.57 & 1.300 & 9.64 \\
5 & -0.00122 & 10.4 & 52.9 & -6.90 & 4.02 & 1.460 & 8.88 \\
\hline
\end{tabular}

The other parameters are given as follows: $m=2.58 \mathrm{~g}, \delta=\alpha_{2}=50 \mathrm{~cm}$

the individual number existing near individual $i$. Let $M_{b}$ and $M_{c}$ be the numbers of the elements in $N_{b}(i)$ and $N_{c}(i)$, respectively.

The model given by (1)-(5) includes several parameters. These parameters were estimated by using an observation data from a water tank experiment. Table 1 shows the parameter estimates obtained by applying the least squares algorithm to an experimental data for a school of five fish.

\section{Simulation results and discussion}

Fish school is defined by Breder ${ }^{5)}$ as a group of individuals in a state of swimming at a uniform speed in a fixed configuration. We investigate a schooling behavior of twenty fish swimming in the two-dimensional free space (i.e., $N_{f}=20$ ). The school is assumed to consist of five groups of individuals, and each group has four individuals with identical parameter values. The values of parameters for each group are given by Table 1 .

In a fish school, it is difficult to know how each individual exchanges information among other individuals around him. For investigating this matter, simulation was carried out by changing the values of $M_{b}$ and $M_{c}$, and some important characteristics of fish school were calculated. The characteristics are the school size $d$, the average speed $v$ of individuals, the average distance $d_{1}$ of the nearest fish to each individual, the average distance $d_{2}$ of the second nearest fish to each individual, and the average ratio $r=d_{2} / d_{1}$. Of these characteristics, $r$ is considered as the degree of the structure of a school. If the school is in complete order, i.e., the school makes a crystal type configuration, then $d_{1}=d_{2}$ and $r=1$ holds. On the other hand, if the schooling configuration is quite random, then we have $r=1.6^{3)}$. It is reported that real data shows $1<r<1.6^{3)}$.

Fig. 1 shows the variation of the school size $d$ with time for various values of $M_{b}$ and $M_{c}$. It is observed from Fig. 1 that $d$ becomes constant as

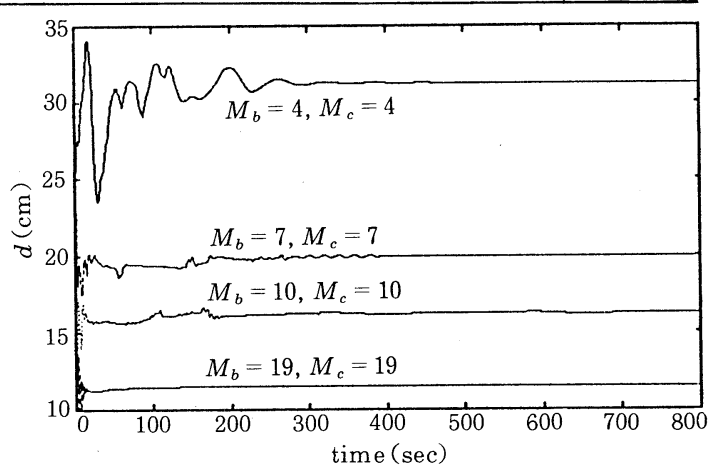

Fig. 1 Time variation of school size for various values of $M_{b}$ and $M_{\mathrm{c}}$

$t \rightarrow \infty$. As $M_{b}$ increases, any individual obtains much information and the total information exchange becomes active within the school. Consequently, the school behavior for large $M_{b}$ becomes a steady state faster than that for small $M_{b}$. Simulation results show that, for $M_{b}<4$, the school is divided into several small schools.

Simulation results also show that the value of $M_{c}$, for $M_{c} \geq 1$, does not give any significant difference on the characteristics of the school. Fig. 2 shows the variation of the school size $d$ with $M_{b}$. Fig. 3 shows the variation of the average speed $v$ with $M_{b}$. The average distances $d_{1}$ and $d_{2}$, and the ratio $r$ are shown in Fig. 4 . These values are the average values of twenty fish, obtained when the school is in stationary condition. It is found that the values of $d, d_{1}$ and $d_{2}$ vary with $M_{b}$.

When a fish school swims in a free water, the shape, the size and other characteristics of the

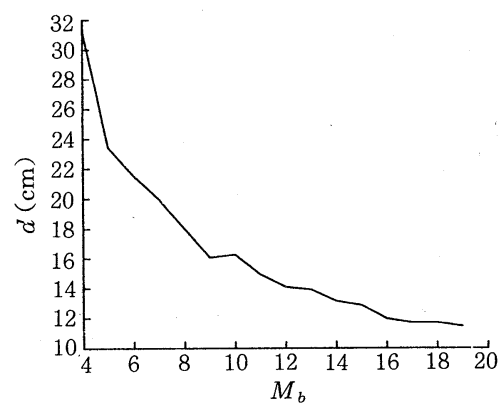

Fig. 2 Variation of school size with $M_{b}$

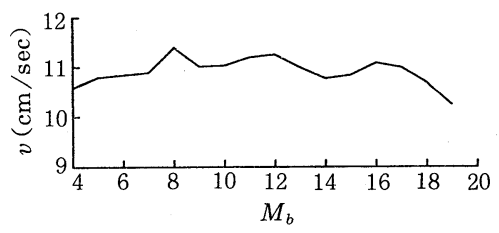

Fig. 3 Variation of average speed with $M_{b}$ 


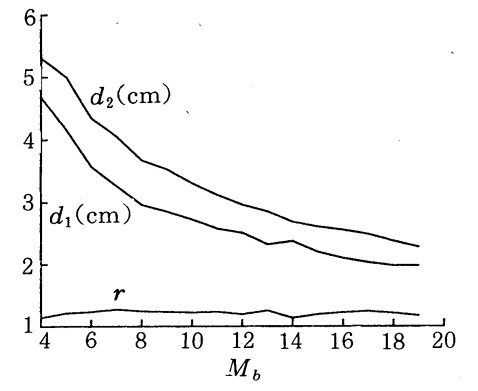

Fig. 4 Variation of $d_{1}, d_{2}$ and $r$ with $M_{b}$

school vary in some moment. These variations are considered to be due to a certain stimulus given by an environmental field. It is interesting to conjecture that these variations are also due to variations in the values of $M_{b}$ and $M_{c}$. This conjecture is based on Balchen's idea of fish movement ${ }^{6)}$. According to his idea, an environmental state gives an influence on the biological state of fish, and the biological state decides fish movement. Further, it is assumed that the values of $M_{b}$ and $M_{c}$ depend on the biological state of fish. The biological state of fish can not be observed. However, we can observe the school size, from which the biological state and the values of $M_{b}$ and $M_{c}$ are expected to be estimated.

\section{Conclusion}

The behavior of a fish school in a free water has been simulated. A special attention has been paid to an autonomous decentralized mechanism of fish school. It is shown that some characteristics of fish school such as the school size and the average distance between two individuals vary with $M_{b}$. However, the average speed of individuals and the degree of school structure given by $r$ do not vary with $M_{b}$ significantly.

This work is partly supported by the Grant-inAid for Scientific Research of the Ministry of Education, Science and Culture of Japan under Grant : Priority-Area Research No. 04218108.

\section{References}

1) N. Sannomiya, H. Nakamine and K: Matuda : Application of System Theory to Modeling of Fish Behavior; Proc. of 29 th IEEE Conf. on Decision and Control, Vol. 5, pp. 2794 2799 (1990)

2) A. Shimada, H. Nakamine and N. Sannomiya : A Study on the Schooling Mechanism of a Fish Behavior Model ; Proc. of 35 th Annual Conf. on ISCIE, pp. 297 298 (1991)

3) B. L. Partridge: The Structure and Function of Fish Schools, Scientific American, June, pp. 90 99 (1982)

4) M. Inoue : Fish Behavior and Fishing Techniques, Koseisha Koseikaku, pp. 188 203 (1978)

5) C. M. Breder: Studies on Social Grouping in Fishes ; Bull. Amer. Mus. Natural Hist., Vol. 117, pp. 399 468 (1959)

6) J. G. Balchen (C. T. Leondes (ed.)) : Modeling, Prediction, and Control of Fish Behavior, Control and Dynamic Systems, Academic Press, pp. 99 146 (1979) 